\title{
Entre a teoria e a prática: visões das assistentes sociais
}

\author{
Between theory and practice: social workers' views
}

Jacqueline Marques ${ }^{1}$

Kathy Mutschen Carvalho ${ }^{2}$

\begin{abstract}
Resumo
Hoje, vivemos uma fase de desenvolvimento científico do serviço social, sendo crucial discutir a importância de uma prática que funcione em sintonia com a teoria. Nesse sentido, este estudo pretende compreender as diferentes perspetivas teóricas que enquadram a prática profissional de uma amostra de assistentes sociais portugueses a partir da perspetiva tripartida de Malcolm Payne. Aplicou-se um questionário online, no ano de 2018, a uma amostra de 54 assistentes sociais. Os resultados mostram que a maioria das assistentes sociais se posiciona numa visão individualista-reformista e terapêutica-reflexiva e apenas uma minoria na visão socialista-coletivista ou mista.
\end{abstract}

Palavras-chave: serviço social, perspetivas teóricas do serviço social, identidade profissional.

\begin{abstract}
Today, we live in a phase of scientific development of social work, and it is crucial to discuss the importance of a practice that works in harmony with theory. In this sense, this study aims to understand the different theoretical perspectives that frame the professional practice of a sample of Portuguese Social Workers based on Malcolm Payne's tripartite perspective. An online questionnaire was applied to a sample of 54 Social Workers, in the year of 2018. The results show that the majority of Social Workers position themselves in an Individualist-reformist and Therapeutic-reflexive vision and only a minority in the Socialist-collectivist or mixed vision.
\end{abstract}

Keywords: social work, theoretical models of social work, professional identity.

\section{Introdução}

Não existe uma conceção única no serviço social, já que são diversas as correntes teóricas presentes na área. Os modelos teóricos são um aspeto central para uma prática profissional refletida, uma vez que garantem que os profissionais uniformizem as suas práticas e possuam um conjunto de orientações que fundamentem o seu trabalho. O estudo que aqui apresentamos pretendeu compreender as diferentes perspetivas teóricas que

\footnotetext{
${ }^{1}$ Professora Auxiliar na Universidade Lusófona de Humanidades e Tecnologias, Instituto de Serviço Social | E-mail: jacqueline.marques@ulusofona.pt

${ }^{2}$ Assistente Social na APPACDM Coimbra | E-mail: kathycarvalho94@gmail.com
} 
enquadram a prática profissional de uma amostra de assistentes sociais portugueses a partir da perspetiva tripartida de Malcolm Payne.

Iniciamos o artigo com uma breve apresentação das vertentes do serviço social de Malcom Payne, seguida de uma exposição, igualmente sucinta, sobre a identidade profissional. De seguida, apresentamos os resultados do estudo e uma reflexão final sobre os mesmos.

\section{Vertentes do serviço social: a visão de Malcom Payne}

Malcolm Payne (2002) defende a existência de três visões que englobam diversas perspetivas de e sobre o serviço social, nomeadamente, a individualista-reformista, a socialista-coletivista e a terapêutica-reflexiva.

$\mathrm{Na}$ perspetiva individualista-reformista, a/o assistente social tem a função de auxiliar os sujeitos a ajustarem-se e adaptarem-se à realidade existente, sendo que o problema central está na pessoa intervencionada, podendo esta visão ser interpretada como uma abordagem clássica (Payne, 2002). Esta visão coloca a/o profissional como agente que fornece serviços de apoio social, diagnosticando as necessidades existentes ou encaminhando o processo para outros órgãos competentes, através de uma "ajuda individual de forma organizada e eficiente" (Payne, 2002, p. 129). A corrente terapêuticareflexiva, surge como estratégia para o fomento das capacidades dos sujeitos, proporcionando-lhes um maior desenvolvimento pessoal e humano. Para o autor, esta visão "vê o serviço social como um auxiliar de indivíduos (e talvez grupos e comunidades) pretendendo alcançar objetivos pessoais, desenvolvimento pessoal e poder sobre o contexto, isto é, identificando e completando de forma satisfatória as suas necessidades e desejos" (Payne, 2002, p.129). Por último, a corrente socialista-coletivista, implica o questionamento da ordem social, considerada como causadora dos problemas e das injustiças sociais, tendo por isso a/o assistente social a função de capacitar as/os clientes para que estes consigam transformar o sistema (Amaro, 2015).

Para Payne (2002) apenas fazendo uso das três conceções em simultâneo é possível gerar uma atuação completa aliando, por um lado, uma perspetiva crítica do sistema e, por outro, uma ação mais focalizada na pessoa.

Salientamos, aqui a visão de Dominelli (1998) que define a existência de três outras vertentes no serviço social: a emancipatória, a adaptativa e, ainda, a terapêutica de ajuda. A primeira procura concretizar a justiça social por meio da mudança social e individual, pelo contrário a segunda pretende que o indivíduo se ajuste e seja capaz de desenvolver 
a sua vida de acordo com as normas e, finalmente, a terceira centra-se na procura do entendimento do indivíduo sobre si, e os outros e o meio.

Desta forma, podemos verificar algumas semelhanças entre ambas as perspetivas, podendo a visão adaptativa se assemelhar à individualista-reformista de Payne, uma vez que se foca na relação direta entre a/o profissional e o sujeito individualizado, sendo a/o profissional o elemento que toma as decisões e orienta o caminho que será traçado na intervenção. Já na visão emancipatória verificam-se pontos em comum com a visão socialista-coletivista, buscando-se uma intervenção focada na justiça social e na transformação da sociedade em prol da justiça e equidade social.

\section{A identidade profissional da/o assistente social em Portugal}

Amaro (2015) considera que as identidades profissionais são "o conjunto de traços comuns que agregam, fecham, produzem sentimentos de pertença e autorizam a que se distinga entre os elementos que fazem parte desse conjunto e os que lhe são exteriores" (p. 86). Numa perspetiva semelhante, Granja (2014) considera que a identidade profissional representa os padrões e diretrizes utilizadas para solucionar, enfrentar ou problematizar a atividade profissional, garantindo "estabilidade, coerência necessária para assegurar a energia que permite a ação e a vontade para agir profissionalmente".

Para Dubar (1997) podemos falar de uma diversidade nas formas identitárias, fruto da relação entre a personalidade individual das/os profissionais e as estruturas políticas, sociais e económicas. Apesar disso o autor sublinha que essas identidades permitem legitimar as práticas profissionais e o reconhecimento entre os pares e outros parceiros.

No que se refere a identidade profissional das/os assistentes sociais, Neto (2000) considera a necessidade de uma reinvenção constante, pois as problemáticas na atualidade não são as mesmas que enfrentaremos num futuro próximo, existindo uma necessidade constante de adaptação de políticas sociais e estratégias de intervenção profissional. A formação tem, portanto, uma tarefa extremamente importante, garantindo que as/os futuros profissionais tenham a capacidade de se modificar e adequar a mudanças constantes. Para isso, deve verificar-se uma procura da teoria como orientação para a ação, permitindo "garantir ao profissional a sua competência profissional, eficácia, legitimidade do processo de trabalho e segurança relativamente às atividades que desenvolve" (Granja, 2014, p. 63).

São diversas as tensões identitárias que as/os assistentes sociais têm que enfrentar, entre elas, a interpretação de contextos e situações muito variadas, envolvendo diferentes 
pessoas e recursos, a necessidade de articular o uso da sua autonomia para a resolução de problemas sociais e a necessidade de cumprir com um conjunto estabelecido de normas e procedimentos, lidar com a tensão que surge no exercício da prática profissional entre as referências propostas na formação e as existentes na prática e a dificuldade em concretizar mudanças, podendo apenas intervir em alguns problemas existentes, não conseguindo em muitos momentos modificar "condições estruturais sociais, económicas, políticas e culturais que geram a exclusão, a pobreza, a doença e o sofrimento" (Granja, 2014, p. 70).

Dubar (1997) considera que as tensões identitárias podem ser amenizadas utilizando

dispositivos de mediação que acompanhem a reconstrução identitária permanente e em tensão; que estabeleçam o diálogo entre as formas identitárias já consolidadas e as novas formas de gestação; que estabeleçam a articulação entre as condições objetivas, as interações socias causadores de tensão e a experiência pessoal e coletiva dos profissionais, entre os sujeitos profissionais, os seus atores coletivos nas suas diferentes configurações, como as escolas, os investigadores e seus produtos cientifico-profissionais (in Granja, 2014, p. 71).

Amaro (2015) desenvolveu um estudo acerca dos perfis identitários dos assistentes sociais, identificando após a análise de um conjunto de entrevistas, dois tipos de perfis ideal-típico de profissionais, o científico-burocrático e o científico-humanista. O perfil científico-burocrático (técnico superior de serviço social) foca-se numa perspetiva mais quantificadora da realidade existente, separando a teoria da prática, e orientando a sua ação para um conjunto de procedimentos estandardizados, eficientes, eficazes e centrados na avaliação de resultados. Este perfil procura "a transformação da prática profissional num exercício tecnocrático, balizado por guias e procedimentos previamente definidos e testados, com a intencionalidade central de demonstrar desempenhos competentes" (Amaro, 2015, p. 119). O perfil científico-humanista (assistente social) orienta a prática segundo uma ligação constante entre a teoria e a prática, sendo a teoria utilizada para compreender a prática e, em seguida, sendo reconstruída. Neste perfil salientam-se outras características como sejam a importância da consciência política, a reflexividade, a intervenção social como uma "arte" e a importância da erradicação dos problemas. 
Pretende-se que este tipo de profissional seja consciente das suas ações e crítico, procurando mobilizar todas as ferramentas para cada situação existente.

Ao analisar estes dois perfis identitários, Amaro (2015) reflete sobre o papel das instituições no modus operandi dos assistentes sociais, questionando até que ponto estas podem influenciar a prática dos profissionais, impondo-lhes "uma postura mais normativa que reflexiva, o que, em contrapartida, oferece ao profissional maior segurança e salvaguarda" (p. 120). Este estudo de Amaro (2015) demonstra que a identidade profissional dos assistentes social em Portugal está ainda a construir-se.

\section{Métodos}

Este estudo procura compreender a perceção que as/os assistentes sociais possuem sobre os conceitos teóricos que enquadram a sua prática, ou seja, analisar, tendo em conta as visões de serviço social categorizadas por Malcom Payne, qual(is) o(s) modelo(s) teórico(s) que informam a prática profissional das/os assistentes sociais

Para a concretização deste estudo utilizamos uma metodologia de natureza descritiva e de cariz misto. $\mathrm{O}$ instrumento de recolha de dados foi o questionário, que foi dividido em duas partes: a primeira parte, de caracterização do sujeito, apresenta questões relativas ao sexo, idade, distrito, concelho, tempo de carreira, tipo de contrato e área de atuação; a segunda parte inclui vinte e sete itens, estando divididos por três blocos de afirmações. Em cada bloco existem três afirmações de cada visão do modelo tripartido de Malcon Payne dispostas de forma aleatória. Ainda nesta segunda parte, incluem-se duas questões: a primeira referente ao modo de tratamento dos indivíduos intervencionados (utentes, beneficiários ou clientes) e a segunda relativa ao modo como o assistente social caracteriza a sua prática (empoderadora, assistencialista ou transformadora). Nesta última pergunta é pedido que justifiquem a opção escolhida.

O questionário foi previamente aplicado a dois respondentes em pré-teste, de forma a averiguar eventuais dificuldades e proceder aos ajustes necessários antes da sua aplicação. Todos os dados recolhidos através do questionário foram tratados e analisados com recurso ao software IBM SPSS 22.

O critério de seleção da amostra passou pela escolha de assistentes sociais a desempenhar funções, independentemente dos seus anos de serviço ou do estatuto profissional. Foi um questionário online que foi enviado, no ano de 2018, por correio eletrónico para um conjunto de assistentes sociais, a quem pedimos para reencaminharem o questionário para outras/os assistentes sociais que conhecessem. Deste modo a amostra, 
não representativa, foi concretizada através de uma amostragem por bola de neve. Estipulamos um período de 3 meses para a recolha de respostas. Foram reunidos um total de 54 questionários válidos.

\section{Resultados}

A amostra é composta por 54 sujeitos, 50 do género feminino e 4 do género masculino, situação que vai ao encontro da realidade da classe profissional em Portugal ${ }^{3}$. Em termos de distribuição geográfica, a amostra inclui assistentes sociais de 14 distritos, sendo na sua maioria de Coimbra (13) e de Lisboa (11). Verifica-se que não há uma distribuição homogénea, existindo contributos de todo o país, de qualquer das formas, assumimos que a prática profissional possui características semelhantes em todo o país, uma vez que a formação obtida e os serviços prestados são similares.

As assistentes sociais da amostra encontram-se na sua maioria numa situação de contrato (46), apenas 8 afirmaram estar em estágio ou noutra situação não identificada.

Tabela 1. Tipo de contrato.

\begin{tabular}{|c|c|c|c|}
\hline & & Frequência & Percentagem \\
\hline \multirow{4}{*}{ Válido } & Contrato & 46 & 85,2 \\
\hline & Estágio & 3 & 5,6 \\
\hline & Outro & 5 & 9,3 \\
\hline & Total & 54 & 100,0 \\
\hline
\end{tabular}

Relativamente à área de atuação, 37 das inquiridas selecionaram a comunidade como opção, dividindo-se as restantes pela saúde (10), educação (2) e justiça (4), havendo ainda 1 caso que não respondeu. Em específico quanto à área da comunidade, optámos por incluir nesta categoria a segurança social, as câmaras municipais e as IPSS ou similares. A inclusão de tantos contextos diferentes numa só área originou a concentração da grande maioria nesta opção. Neste sentido, poderia ter sido mais útil, distinguir diferentes contextos em vez de os agregar.

Após a análise das respostas, concluiu-se que das 54 inquiridas, 16 se posicionaram na visão individualista-reformista, 26 na terapêutica-reflexiva e 3 na socialista-coletivista. Importa salientar que para incluir as inquiridas em determinada visão verificamos qual era a visão em que cada uma possuía a maioria das suas respostas. Tendo em conta que cada assistente social inquirida deu respostas que correspondiam às três visões, nunca se

\footnotetext{
${ }^{3}$ Pelo que assumiremos o género feminino nas palavras utilizadas nesta análise.
} 
posicionando totalmente numa delas, para efeitos de análise, consideramos que a visão maioritária de cada sujeito corresponde aquela onde escolheu o maior número de respostas. Em 9 casos, houve empate no número de respostas de duas ou mais visões, pelo que estes foram considerados mistos.

Tabela 2. Número de casos de cada visão

\begin{tabular}{lll}
\hline \multirow{2}{*}{ Visão com respostas maioritárias } & \multicolumn{2}{l}{ Válido } \\
\hline & $\mathrm{N}$ & Percentagem \\
\hline Individualista & 16 & $30 \%$ \\
Socialista & 3 & $5 \%$ \\
Terapêutica & 26 & $48 \%$ \\
Misto & 9 & $17 \%$ \\
\hline
\end{tabular}

Em seguida apresentamos as relações encontradas entre as visões maioritárias da prática profissional e as características dos inquiridos.

Existem 16 mulheres na visão individualista-reformista, 1 na socialista-coletivista, 25 na terapêutica-reflexiva e 8 que com visões mistas. Quantos aos homens dois posicionam-se na visão socialista-coletivista e os outros dois sujeitos na terapêuticareflexiva e mista.

Tabela 2. Cruzamento entre o sexo e a visão maioritária

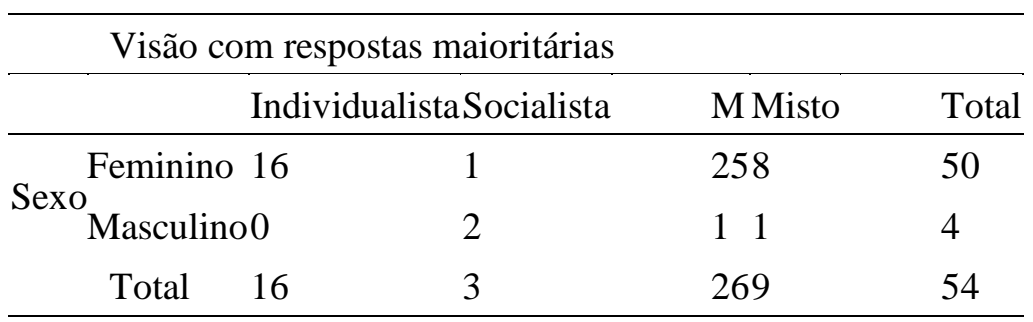

O teste de Qui-quadrado de Pearson indica-nos que existem diferenças entre o sexo no que respeita às visões sobre a prática $(\mathrm{p}=0.001)$. Contudo, dado o número reduzido de indivíduos do sexo masculino, podemos supor que este efeito não retrata a realidade e deverá ser investigado em amostras de maior dimensão.

Os sujeitos com uma visão tendencionalmente individualistas-reformistas têm em média 35 anos (desvio padrão 6.830), os socialistas-coletivistas 46 anos (desvio padrão 2.646), os terapêuticos-reflexivos detêm uma média de 32 anos (9.227) e, por fim, os mistos 38 anos (desvio padrão 9.391). 
A distribuição das idades dos sujeitos parece variar nas diferentes visões. Na visão socialista-coletivista, verifica-se que os 3 sujeitos têm mais de 40 anos. Podemos observar também que é na visão terapêutica que se encontram os sujeitos mais jovens da amostra, sendo que um número elevado está abaixo dos 30 anos. Estas diferenças poderiam ser explicadas por fatores relacionados com a formação ou o contexto de trabalho, contudo não recolhemos informações suficientes neste trabalho para construir uma hipótese suficientemente sólida nesta matéria. O teste de Kruskal-Wallis confirma que, de facto, existem diferenças significativas em função da idade $(\mathrm{P}=0.033)$.

Tabela 4. Relação entre a idade e a visão maioritária.

\begin{tabular}{|c|c|}
\hline \\
\hline \multicolumn{2}{|c|}{$\begin{array}{l}\text { Idade } \\
\text { Visão com respostas maioritárias MédiaN Desvio Padrão }\end{array}$} \\
\hline Individualista & $35,13 \quad 166,830$ \\
\hline Socialista & $46,0032,646$ \\
\hline Terapêutica & $32,23 \quad 269,227$ \\
\hline Misto & $38,2299,391$ \\
\hline Total & $34,85548,905$ \\
\hline
\end{tabular}

A distribuição do tipo de visão em função do distrito de pertença parece não seguir nenhum padrão, o que é confirmado pelo valor da significância no teste de qui-quadrado de Pearson $(\mathrm{P}=0,617)$. Isto significa que, nesta amostra, a localização geográfica não é um fator determinante para o tipo de visão sobre a prática profissional dos assistentes sociais.

Existem 15 inquiridas em situação de contrato e que se posicionam na visão individualista-reformista, 25 na terapêutica-reflexiva, 2 na socialista-coletivista e, ainda 4 que são mistos. Já no caso do estágio, os 3 sujeitos encontram-se na visão terapêuticareflexiva (1) ou são mistos (3). Restando ainda 5 respondentes que afirmam estar noutro tipo de situação. O teste de Qui-quadrado de Pearson indica-nos que existem diferenças entre o tipo de contrato no que respeita às visões sobre a prática $(\mathrm{p}=0.006)$. Contudo, dado o número reduzido de sujeitos em outra situação além do contrato, podemos supor que este efeito não retrata a realidade e deverá ser investigado em amostras de maiores dimensões. 
Tabela 5. Relação entre o tipo de contrato e a visão maioritária.

\begin{tabular}{rllcccc} 
& & \multicolumn{4}{c}{ Visão com respostas maioritárias } & \multirow{2}{*}{ Total } \\
\cline { 3 - 6 } Tipdividualista & Socialista & Terapêutica & Misto & \\
\hline \multirow{2}{*}{ Tipo contrato } & Contrato & 15 & 2 & 25 & 4 & 46 \\
& Estágio & 0 & 0 & 1 & 2 & 3 \\
Total & Outro & 1 & 1 & 0 & 3 & 5 \\
\hline
\end{tabular}

Relativamente à área de atuação, parece não existir uma tendência de resposta, que permita atribuir à visão sobre a prática uma área de atuação das assistentes sociais. Esta questão é confirmada no teste de Qui-quadrado de Pearson, apresentado na tabela $\mathrm{x}(\mathrm{P}=$ $0.178)$.

A distribuição do tempo de carreira não parece variar consoante as diferentes visões. Na visão socialista-coletivista, verifica-se que 3 assistentes sociais com uma média de 19 anos de carreira; verifica-se ainda que na visão terapêutica, individualista e mista as médias de tempo de carreira são de, respetivamente, 9, 10 e 11 anos. O teste de Kruskal-Wallis confirma que não existem diferenças significativas em função da idade $(\mathrm{P}=0.130)$.

Tabela 6. Relação entre o tempo de carreira e a visão maioritária.

Tempo carreira

\begin{tabular}{lllc}
\hline Visão com respostas maioritárias & Média & $\mathrm{N}$ & Desvio Padrão \\
\hline Individualista & 10,60 & 15 & 7,219 \\
Socialista & 19,33 & 3 & 2,082 \\
Terapêutica & 8,85 & 26 & 7,103 \\
Misto & 11,44 & 9 & 9,126 \\
Total & 10,38 & 53 & 7,568 \\
\hline
\end{tabular}

Quanto à forma como intitulam a população alvo, verificamos uma prevalência do termo "utentes" com 36 (67\%), optando 7 pela opção "beneficiários (13\%) e 11 por “clientes" (20\%). Quanto à dispersão dos conceitos pelas várias visões, destacamos um maior número a utilizarem os termos "utente" na visão terapêutica, bem como na individualista, no entanto, o teste de Qui-quadrado de Pearson não aponta no sentido de existirem diferenças significativas $(\mathrm{P}=0,254)$. 
Tabela 7. Relação entre o público-alvo e as visões maioritárias.

\begin{tabular}{|c|c|c|c|c|c|c|}
\hline & \multicolumn{4}{|c|}{ Visão com respostas maioritárias } & \multirow{2}{*}{ Total } \\
\hline & & Individualista & Socialista & Terapêutica & Misto & \\
\hline \multirow{3}{*}{$\begin{array}{l}\text { Designação público- } \\
\text { alvo }\end{array}$} & Utentes & 10 & 1 & 18 & 7 & 36 \\
\hline & Beneficiários & 3 & 0 & 2 & 2 & 7 \\
\hline & Clientes & 3 & 2 & 6 & 0 & 11 \\
\hline Total & & 16 & 3 & 26 & 9 & 54 \\
\hline
\end{tabular}

Verifica-se que existem relações significativas entre o tipo de prática relatada e as visões maioritárias identificadas, através das afirmações do questionário $(\mathrm{P}=0,009)$. De facto, 19 das assistentes sociais que se intitularam profissionais empoderadores, foram identificados como sendo integrantes da visão terapêutica-reflexiva.

No caso, das que se intitulam assistencialistas (10) metade enquadra-se na visão individualista-reformista, aspeto também confirmado pelo posicionamento de Payne que enfatiza nessa visão a produção de serviços de assistência aos indivíduos, com o intuito de melhorar os seus problemas pessoais e promover o ajustamento desta sociedade.

Por fim, quanto aos sujeitos que se consideram transformadores/críticos (18), 7 incluem-se na visão individualista. Esta situação constitui uma contradição, pois considerando-se transformadores/críticos, pressupõem-se que a sua prática passe pela criação de mudança na sociedade, uma vez que são esses os grandes pilares da visão socialista-coletivista, pretendendo a alteração das estruturas e do sistema, no entanto, as respostas dadas apontam para uma interpretação do termo como sendo a transformação/modificação dos indivíduos intervencionados. Desta forma, podemos observar que alguns dos posicionamentos na visão transformador/crítica, apresentam as características de uma prática assistencialista. De forma, a justificar este mesmo facto, apresentemos em seguida algumas respostas que vão neste sentido, ou seja, profissionais que se consideram transformadores/críticos, mas que o seu discurso se insere numa prática assistencialista: "objetivo de transformação do ser humano, capacitando-o."; "transformadora na medida em que contribuo para a mudança de comportamentos"; "tentamos transformar as pessoas a mudar o seu comportamento, atitudes de forma a ter um papel mais ativo na sociedade". 
Tabela 8. Relação entre o tipo de prática e as visões maioritárias.

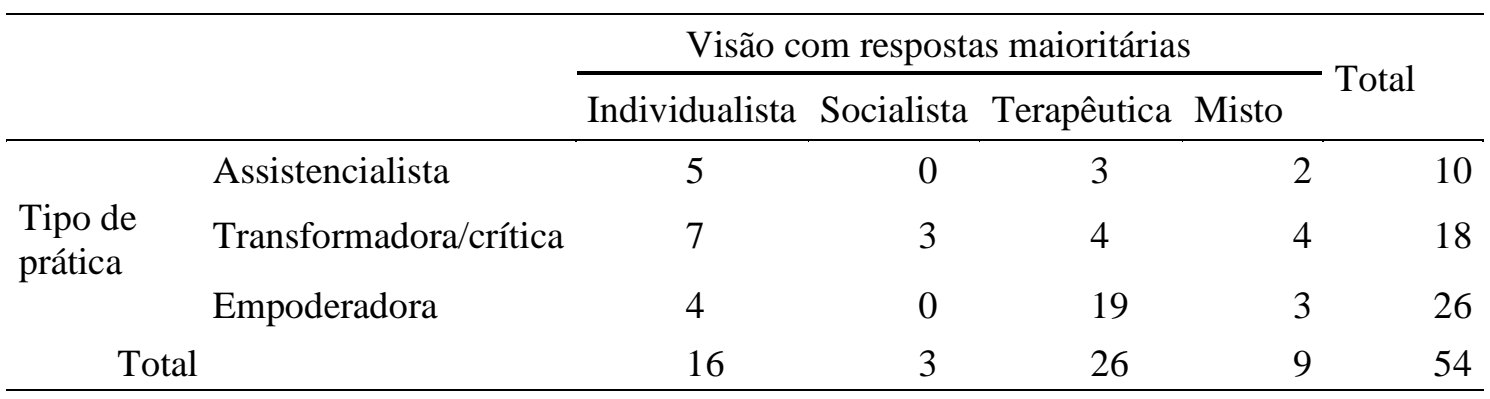

\section{Considerações finais}

Os questionários recolhidos mostraram que com alguma frequência as assistentes sociais se posicionam tendencialmente, numa determinada perspetiva teórica específica. Segundo Payne para uma prática mais eficiente o mais recomendável seria a adoção de uma abordagem mista, ou seja, que englobe aspetos característicos das três visões, no entanto, os dados recolhidos não refletem este cenário. Embora, algumas assistentes sociais se enquadrem numa perspetiva mista (17\%), a maioria inclina-se para uma visão individualista-reformista $(30 \%)$ ou terapêutica-reflexiva (48\%). Quanto à visão socialista-coletivista apenas $5 \%$ das assistentes sociais se posicionam nesta perspetiva, embora, como já referimos, a interpretação que fazem da mudança não se enquadra nesta perspetiva.

Este estudo apresenta algumas limitações que importa identificar, tais como: uma amostra pequena; a utilização de um instrumento de construção própria, que teria beneficiado de um período mais longo de teste; a utilização de um questionário online que restringiu o leque de potenciais inquiridos, seja, por falta de acesso à internet ou pouca familiaridade com as ferramentas digitais; e, ainda, a existência de um número limitado de estudos diretamente relacionados com este tema.

Apesar dessas limitações consideramos que este estudo permitiu desenhar um quadro sobre as visões dominantes nas assistentes sociais da nossa amostra e demonstrar a necessidade de repensar a formação (inicial e continua) e a intervenção desenvolvida por estas profissionais. De facto, a maioria encara a prática dos assistentes sociais segundo uma visão adaptativa (Dominelli, 1998) e individualista-reformista (Payne, 2002). A visão adaptativa (Dominelli, 1998) e individualista-reformista (Payne, 2002) considera que a intervenção social procura ajustar os indivíduos às normas e onde o profissional detém um amplo poder de decisão, com o intuito de concretizar (através das 
suas decisões) a justiça e equidade social. Aqui a ação profissional assume uma posição de controle e de reprodução social, de psicologização e individualização das relações sociais e de moldagem das necessidades sociais de acordo com os recursos institucionais existentes. Convém registar a existência, embora reduzida, de profissionais com práticas que ultrapassando o papel de mediador entre necessidades e ofertas institucionais. Esta visão emancipatória de realização da justiça social, implica uma prática transformacional e capacitadora que visa "promover o bem-estar através da transformação das atuais configurações da desigualdade e do mal-estar que inibe as pessoas de realizarem seu pleno potencial" (Dominelli, 1998, p. 5). Uma visão próxima da perspetiva socialista-coletivista da profissão que Payne apresenta "contrariando as práticas que criam opressão e desfavorecimento, o trabalho social tenta, deste modo, incrementar relações mais igualitárias na sociedade" (2002, p. 20-21).

Este resultado leva-nos a refletir sobre a tendência para a tecnificação da prática profissional, concebida como "neutra", despojada do carácter político o que, entre outras consequências, permite reduzi-lo a uma vertente assistencialista que a distancia dos direitos. Esta tendência para uma identidade cientifico-burocrática (Amaro, 2015) da profissão esvazia a mesma do seu potencial transformador e da sua capacidade para influenciar (e transformar) as políticas sociais. Se tivermos em conta a perspetiva de Lipsky (1976, in Marques, 2016), segundo a qual estes profissionais agem, decidem, criam rotinas e mecanismos para responder a dúvidas e a omissões da lei que surgem no decorrer da implementação, na relação direta que se estabelece com a população beneficiária, tornando-os "fazedores de políticas", então devemos questionar-nos se a visão socialista-coletivista não deveria estar mais presente na prática profissional (mesmo que aliada com outras). Perante os dados recolhidos, devemos questionar-nos se são de facto as instituições que não permitem que as assistentes sociais sejam agentes de mudança ou se o problema está relacionado com outros fatores como, por exemplo, a formação.

$\mathrm{Na}$ atualidade as exigências colocadas ao serviço social perante os novos problemas sociais são variados: por um lado, exige-se que responda a problemas em constante mutação e, por outro lado, impõem-se respostas cada vez mais rápidas que encurtem o tempo de intervenção e aumentem o número de pessoas atendidas. A despolitização da ação profissional, juntamente com a excessiva inclinação para a quantificação dos resultados da prática, sobrevalorizando a ação técnica e operativa, em detrimento da análise real dos impactos da intervenção na (mudança) pessoa e no contexto, permite o 
surgimento de profissionais que são meros gestores de recursos. Adiam a sua função relacional e de empoderamento levando a uma "funcionarização do Serviço Social" (Bouquet e Garcette, 2005, p. 41) que para os autores Branco e Amaro (2011, p. 665) pode ser traduzido no emergente "Serviço Social Ativo", que centra as funções do assistente social numa ação burocrática, administrativa, de coordenação e avaliação, deixando em segundo plano as funções de acompanhamento.

Esta perspetiva do Serviço Social distancia-se da definição aprovada pela Assembleia Geral da IFSW e da IASSW em julho de 2014:

O serviço social é uma profissão de intervenção e uma disciplina académica que promove o desenvolvimento e a mudança social, a coesão social, o empowerment e a promoção da Pessoa. Os princípios de justiça social, dos direitos humanos, da responsabilidade coletiva e do respeito pela diversidade são centrais ao serviço social. Sustentado nas teorias do serviço social, nas ciências sociais, nas humanidades e nos conhecimentos indígenas, o serviço social relaciona as pessoas com as estruturas sociais para responder aos desafios da vida e à melhoria do bem-estar social.

De modo a concretizar esta definição são, hoje, diversos os desafios enfrentados. Um deles refere-se à capacidade de os assistentes sociais aliarem as práticas centradas na instrumentalidade e nos resultados, com as práticas relacionais, intrínsecas à profíssão. Só assim, será capaz de responder às novas exigências sem colocar em causa a identidade e conteúdo da profissão, e poderá desenvolver a preconizada intervenção individualizada (de responsabilização) sem a dissociar dos contextos e fatores sociais em que os indivíduos se integram, procurando a mudança ao nível do indivíduo e da estrutura.

Não podemos, no entanto, esquecer que na contemporaneidade existem cada vez mais indivíduos a vivenciar situações de precariedade que colocam em causa a sua sobrevivência. Neste contexto de crise, as práticas de distribuição e garantia de rendimentos são tão necessárias como as ações de promoção e empoderamento. Soulet (2007, p. 11-14) apresenta dois tipos de intervenções sociais que podem ser conjugadas: 
a generativa e a paliativa. A primeira tem um carácter de promoção da cidadania, desenvolvimento de capacidades, empoderamento e autonomização dos indivíduos. A segunda garante uma ação mais assistencial (centrada na redução de risco) e, também, de enquadramento dos indivíduos que estão numa situação de ausência de possibilidade de inserção social, fruto de percursos biográficos constrangedores e destrutivos, falta de recursos materiais, relacionais e pessoais, o que exige por parte do profissional um acompanhamento mais personalizado e reforçado, podendo mesmo ter de ser prolongado. Duas formas de intervir que terão que se enlaçar e complementar.

Deste modo e seguindo o pensamento de Dominelli:

o Serviço Social atravessa um tempo de turbulência. Necessita de uma nova visão que avance com uma cidadania activa para os pobres - uma cidadania de iguais, que requer uma mudança pessoal e estrutural da ordem social existente (...) Estes procedimentos têm que ser substituídos por outros enraizados na equidade entre pessoas que partilham recursos, se tratam mutuamente com dignidade e respeitam os recursos físicos e sociais do planeta como uma herança de todos e de cada um e da comunidade. Esta é a base de uma nova visão capacitadora do Serviço Social (2004, p. 253).

O assistente social é um profissional que facilita e proporciona o acesso aos direitos e contribui para a equidade e justiça social. Para Faleiros esta perspetiva para além de fortalecer a cidadania permite uma "articulação da dimensão política com a dimensão de serviços, não se reduzindo o Serviço Social, nem a relações psicológicas nem a relações burocráticas para acesso a determinados benefícios" (1999, p. 169).

Esta "recolocação" da dimensão política do e no Serviço Social apenas poderá surgir se existir um investimento no conhecimento da complexa realidade contemporânea e da diversidade de processos que a produzem. Uma investigação que deve ser aliada a uma formação atualizada aos novos profissionais e aos que já se formaram. 


\section{Referências bibliográficas}

Amaro, I. (2015). Urgências e Emergências do Serviço Social: fundamentos da profissão na contemporaneidade. Universidade Católica Editora.

Bouquet e Garcette (2005). Assistante Sociale Aujourd'hui. Maloine.

Branco e Amaro (2011). As práticas do «Serviço Social Activo» no âmbito das novas tendências da política social: uma perspectiva portuguesa. In Serviço Social \& Sociedade, $n .^{\circ}$ 108. Out/ dez, 656-679.

Dominelli, L. (1998). Anti-Oppressive Practice in Contex. In R. Addams; L. Dominelli e M. Payne (eds.), Social Work: Themes, issues and critical debates (pp.3-22). Mac Millan Press.

Dubar, C. (1997). A socialização: a construção das identidades sociais e profissionais. Porto editora

Faleiros, V. (1999). Os desafios do serviço social na era da globalização. In Serviço Social \& Sociedade,v. 20, n. 61, 153-187.

Granja, B. (2014). Contributos para a análise das formas identitárias dos Assistentes Sociais. In $\mathrm{M}^{\mathrm{a}}$ Irene Carvalho e Carla Pinto (coord.), Serviço Social Teorias e Práticas (pp.57-83). Pactor.

Marques, J. (2016). Itinerário de uma política: olhares sobre o rendimento social de inserção no concelho de Aveiro [Tese de doutoramento em Serviço Social, Universidade Lusíada]. Repositório institucional da Universidade Lusíada. http://hdl.handle.net/11067/2531

Neto, J.P. (2000). Método e teoria nas diferentes matrizes do serviço social. In Elisabete Borgianni e Carlos Montaño (orgs.). Metodologia y servicio social (pp.51-92). Cortez editora.

Payne, M. (2002). Social Work Theories and Reflective Practice. In R. Adams, L. Dominelli, \& M. Payne, (ds.), Social Work: themes, issues and critical debates (pp. 119137). Palgrave.

Soulet, M. (2007). O Trabalho Social Paliativo: entre redução de risco e integração relativa. In Cidades, Comunidades e Territórios, 15,11-27. 